\title{
Interactions between Temperament, Stress, and Immune Function in Cattle
}

\author{
N. C. Burdick, ${ }^{1}$ R. D. Randel, ${ }^{2}$ J. A. Carroll, ${ }^{1}$ and T. H. Welsh Jr. ${ }^{3}$ \\ ${ }^{1}$ Livestock Issues Research Unit, USDA, ARS, Lubbock, TX 79403, USA \\ ${ }^{2}$ Texas AgriLife Research, Texas A\&M System, Overton, TX 75684, USA \\ ${ }^{3}$ Texas AgriLife Research, Texas A\&M System, College Station, TX 77843, USA \\ Correspondence should be addressed to T. H. Welsh Jr., twelsh@cvm.tamu.edu \\ Received 19 January 2011; Accepted 10 March 2011 \\ Academic Editor: Frank Seebacher
}

Copyright $\odot 2011$ N. C. Burdick et al. This is an open access article distributed under the Creative Commons Attribution License, which permits unrestricted use, distribution, and reproduction in any medium, provided the original work is properly cited.

The detrimental effects caused by stressors encountered by animals during routine handling can pose economic problems for the livestock industry due to increased costs ultimately borne by the producer and the consumer. Stress adversely affects key physiological processes of the reproductive and immune systems. In recent years stress responsiveness has been associated with cattle behavior, specifically temperament. Cattle with more excitable temperaments, as measured by chute score, pen score, and exit velocity (flight speed), exhibit greater basal concentrations of glucocorticoids and catecholamines. Similar to stressed cattle, more temperamental cattle (i.e., cattle exhibiting greater exit velocity or pen and chute scores) have poorer growth performance, carcass characteristics, and immune responses. Thus, understanding the interrelationship of stress and temperament can help in the development of selection and management practices that reduce the negative influence of temperament on growth and productivity of cattle. This paper discusses the relationship between stress and temperament and the developing evidence of an effect of temperament on immune function of cattle that have been handled or restrained. Specifically, the paper discusses different methodologies used to measure temperament, including chute score, pen score, and exit velocity, and discusses the reaction of cattle to different stressors including handling and restraint.

\section{Introduction}

The detrimental effects caused by stressors encountered by animals during routine handling can pose economic problems for the livestock industry due to increased costs ultimately borne by both the producer and the consumer. An increased secretion of stress-related hormones in response to physical and psychosocial stressors associated with livestock management procedures such as weaning, castration, transportation, and regrouping can adversely affect growth, reproduction, and immune functions [1-6]. The behavioral response of livestock to handling can also negatively affect management and production as wilder cattle can increase the risk of injury to both the cattle and the producer [7]. Temperament is defined as the reactivity of cattle to humans and novel environments [8]. More temperamental or wilder cattle have greater basal concentrations of stress hormones, decreased growth rates and average daily gain, and weaker immune responses to pathogens [9-11].
Many factors contribute to whether an animal perceives situations as stressful, including development history and prior experience [12]. Based on these factors, the animal's response to a stressor can be beneficial or harmful. For example, the stress response produced to help an animal evade a predator is helpful, as it actives the flight-or-flight response that supports actions that help to increase the chances of survival. In contrast, the stress response to handling during management procedures may be harmful, as it may cause the animal to injure itself or a worker, and the elevated stress hormones may inhibit physiological systems such as reproduction and immunity. Both Le Neindre et al. [13] and Grandin [14] state that both genetic characteristics and prior experience influence how animals react to humans. Boandl et al. [15] found an increase in cortisol concentrations in response to handling. Those investigators also found differences between the responsiveness of calves to handling, noting that calves that had greater human contact previously had a lesser cortisol response and were less responsive than 
those that had less human contact. Grandin [14] proposed that rough handling may be more stressful to temperamental animals than to those animals that are calmer. However, while repeated handling may reduce the reaction of animals to the exposure to those specific managerial tasks, it does not necessarily reduce an animal's response to other novel experiences [14]. Additionally, repeated handling may not reduce the reactivity of more temperamental cattle [14]. Therefore, more temperamental cattle may be better suited for environments where handling is limited, while calmer cattle may be better suited for operations wherein intensive handling is an aspect of the production system.

\section{Primer on Stress Biology}

Hans Selye appears to have been the first biomedical author to use the term stress, a term previously applied in the fields of engineering and physics. In his landmark article in Nature, Selye described a physiological triad that is common to all chronic stressors: (1) thymicolymphatic involution, (2) adrenal enlargement, and (3) gastric ulceration [16]. In 1932 Walter Cannon further clarified the definition of stress by coining the term homeostasis, derived from Claude Bernard's term milieu intérieur; yet, Cannon never actually used the term "stress" $[17,18]$. Selye alluded to the phenomenon of homeostasis in his article in which he termed the efforts of an organism to return to homeostasis as the "general adaptation syndrome" [16]. However, Selye focused on responses of the adrenal cortex, mainly the production of cortisol, while Cannon was more interested in the sympathetic nervous system's role in the stress response $[18,19]$. It is now well understood that both hypothalamicpituitary-adrenal axis and the sympathetic nervous system play significant roles in the body's response to stressors. The classical definition of stress used by Selye has been modified over time in order to reflect the progression in our knowledge base regarding the biology of stress. For the purposes of this paper, stress is currently defined as "a state in which homeostasis is actually threatened or perceived to be so; homeostasis is re-established by a complex repertoire of behavioral and physiological adaptive responses of the organism" [20]. The stress response is stimulated by a stressor and affects the body through activation of the hypothalamic-pituitary-adrenal axis (HPA axis) system and the sympathetic nervous system (more specifically the sympathomedullary system) [21]. Stressors are any internal or external stimuli or threat (physical, psychological, or chemical) that disrupts homeostasis [22, 23]. In response to this altered state, the stress response is activated in order to help the body cope with the threat and return to or maintain homeostasis.

\subsection{Hypothalamic-Pituitary-Adrenal (HPA) Axis. In} response to stressful stimuli, higher brain centers stimulate neurons in the paraventricular nucleus (PVN) of the hypothalamus, resulting in the synthesis and secretion of corticotrophin-releasing hormone $(\mathrm{CRH})$ and vasopressin (VP; Figure 1) $[4,24,25]$. Increased concentration of CRH and/or VP in the hypothalamic-hypophyseal portal blood exposes the anterior pituitary gland's corticotrophs to these neurohormones that activate the adrenal axis. Upon stimulation by $\mathrm{CRH}$, corticotrophs within the anterior pituitary synthesize and secrete ACTH into the circulation $[4,26]$. Via endocrine mechanisms, ACTH stimulates the production of glucocorticoids by the adrenal cortex $[4,27]$. In most mammals such as humans, cattle, and pigs the primary glucocorticoid is cortisol; however, in rodents the primary glucocorticoid is corticosterone. Upon adrenocortical stimulation by ACTH, glucocorticoids are released and distributed via the circulatory system and act systemically to produce a variety of effects depending on (1) the amount of hormone secreted, (2) the duration of secretion, (3) the peripheral blood concentration of cortisol binding globulin, (4) the relative abundance of glucocorticoid receptors in the target tissue, (5) the tissue in which they exert their effect, and (6) the extent of excretion of glucocorticoid metabolites. Glucocorticoids are also responsible for negative feedback on both the hypothalamus and the pituitary by inhibiting synthesis and/or secretion of $\mathrm{CRH}, \mathrm{VP}$, and $\mathrm{ACTH}$, and perhaps as well as expression of the CRH [22]. In contrast, glucocorticoids have been demonstrated to increase the expression of both the vasopressin V1b and V1a receptor [28, 29]. This suggests that CRH and VP are regulated differently. Thus VP can stimulate production of ACTH even when $\mathrm{CRH}$ concentrations are low, to help overcome downregulation of the $\mathrm{CRH}$ receptor.

In the absence of stressor stimulation, $\mathrm{CRH}$ and VP are released at a frequency of approximately 2 to 3 secretory episodes per hour, in a circadian, pulsatile manner, with greater pulse amplitudes in the early morning [30]. The release of CRH and ACTH can be modulated or altered due to changes in lighting, feeding schedules, activity, and ultimately stress [30]. In nocturnal animals, such as rodents, the circadian rhythm of secretion is reversed (i.e., cortisol is greater after dusk in early evening) [31].

Glucocorticoids are transported through the circulatory system by carrier proteins that prevent degradation. Carrier proteins also allow glucocorticoids to be available quickly after induction of the stress response. Albumin is the major carrier protein for cortisol, but cortisol can also be transported by cortisol binding globulin (transcortin). Approximately $1-10 \%$ of cortisol circulates as a "free" steroid $[31,32]$. Tissues also have the ability to increase or decrease available cortisol within cells through $11 \beta$ hydroxysteroid dehydrogenase (HSD11 $\beta$ ) enzymes, which convert cortisone to cortisol (type I) and vice versa (Type II) [32].

Glucocorticoids can bind to both the mineralocorticoid receptor (MR) and the glucocorticoid receptor (GR). When concentrations of glucocorticoids are high enough to fully saturate the MR, glucocorticoids will bind to the GR, resulting in many of the actions of glucocorticoids on the HPA axis and other body systems [4]. The MR is found in some limbic brain areas such as the hippocampus as well as the heart, kidney, and colon. The GR is ubiquitously expressed within the body $[4,33]$. There are two major GR variants: GR- $\alpha$ and GR- $\beta[33,34]$. The GR- $\beta$ does not have 


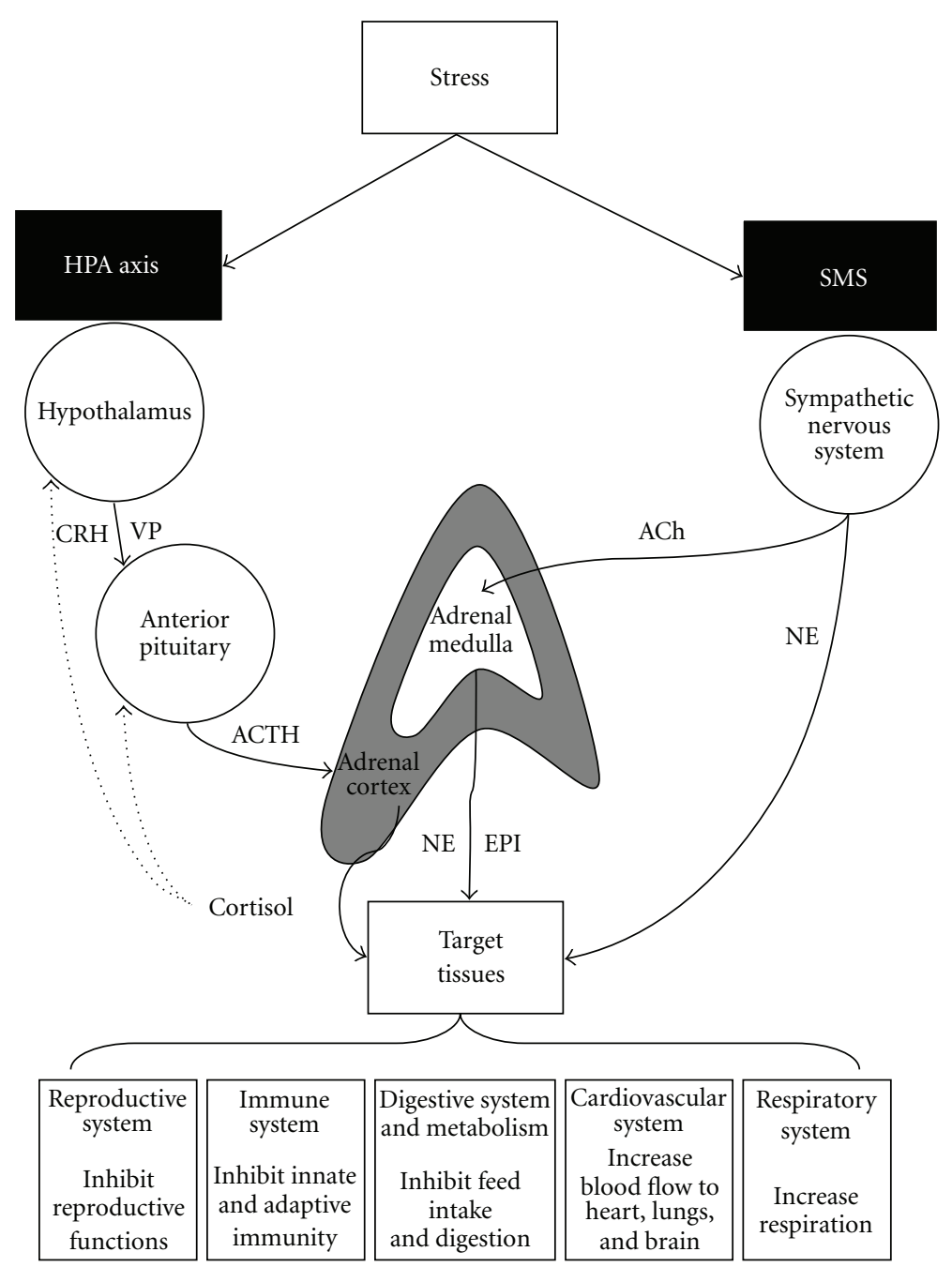

FIGURE 1: Schematic representation of the hypothalamic-pituitary-adrenal (HPA) axis and sympathomedullary system (SMS) response to stress. CRH: corticotrophin releasing hormone; VP: vasopressin; ACTH: adrenocorticotropic hormone; ACh: acetylcholine; NE: norepinephrine; EPI: epinephrine.

the ability to bind glucocorticoids as it is missing the C6 terminus of the protein (i.e., ligand binding domain) [31]. However, it has the ability to bind to the GR antagonist, RU486, and is believed to act as a negative regulator of GR- $\alpha$ [33]. The GR- $\alpha$ variant is the classical glucocorticoid receptor and will be referred to as GR for the remainder of this review.

The GR is a cytoplasmic receptor that remains inactivated by heat shock proteins $90,70,23$, and immunophilins $[5,31]$. Following the binding of glucocorticoids to the cytoplasmic GR, the receptor undergoes a transformational change resulting in the exposure of the nuclear translocation signal [35]. Once in the nucleus the GR will bind to glucocorticoid response elements (GREs) and negative GREs (nGREs) on DNA, allowing for the direct regulation of gene expression. Additionally, the GR can inhibit transcription through protein-protein interactions with transcription factors, regulate signaling through membrane associated receptors and second messengers and also has the ability to change the stability of mRNA molecules in cells and the electrical potential of neuronal cells $[30,32]$.
The binding of glucocorticoid to the GR results in the modulation of gene expression (increase or decrease transcription) of numerous genes, with the effects being tissue-specific. Genes related to immune function that are specifically regulated by glucocorticoids, which will be described in more detail in later sections, include both pro- and anti-inflammatory cytokines, prostaglandin synthesis enzymes, and cell adhesion molecules [35, 36]. Prostaglandin synthesis enzymes are important for blood vessel remodeling to allow for vasodilation and diapedesis of leukocytes (squeezing of leukocytes between two endothelial cells). Cell adhesion molecules allow for the initial binding of leukocytes to the endothelial cells and for the strong binding that precedes diapedesis.

2.2. Sympathomedullary System (SMS). The sympathetic nervous system is activated in response to many stressors in parallel to, and often prior to, stimulation of the HPA axis. Upon stimulation, noradrenergic neurons in the brain and 
postganglionic sympathetic neurons innervating peripheral organs (e.g., heart, vasculature, kidneys, gut, and adipose) secrete norepinephrine into the circulation, resulting in increased blood pressure, heart rate, and respiration rate (Figure 1). Additionally, nerve impulses in higher cortical centers within the brain relay messages through the limbic system resulting in the release of norepinephrine, serotonin, and acetylcholine, which activate the PVN [23]. In conjunction with these actions, preganglionic sympathetic fibers innervating the adrenal medulla stimulate the production and secretion of epinephrine and norepinephrine via acetylcholine [21]. The proportion of epinephrine to norepinephrine secreted can vary by animal species. In most mammals, including humans and cattle, a majority of the catecholamine secreted from the adrenal medulla is epinephrine, with limited norepinephrine. An additional subset of vagal and sacral parasympathetic efferent nerves is activated which mediate the gut response to stress [30].

The sympathetic nervous system regulates many functions in the body including the cardiovascular, gastrointestinal, respiratory, and renal systems, all of which can be modulated in response to SMS activation [5]. An increase in epinephrine concentrations in the brain serves as an alarm system, resulting in a decrease in neurovegetative activities (e.g., eating and sleeping) and the activation of the stress response (HPA axis activation) [30]. The secretion of norepinephrine within the brain also activates the fear behaviors and enhances long-term memory and storage of adversely charged emotions in the hippocampus [30, 35].

2.3. Interactions between the HPA Axis and the SMS. The responses of the HPA axis and the SMS to stress are highly concordant. In response to most stressors both systems are activated and have the ability to synergistically affect the response of each other. For example, reciprocal connections exist between the norepinephrine and CRH systems in the brain, allowing for each hormone to activate the other [30]. The release of norepinephrine, serotonin, and acetylcholine in the brain stimulates the PVN, resulting in the secretion of $\mathrm{CRH}$ [23]. In this manner norepinephrine can modulate the release of ACTH and subsequently glucocorticoids [37]. Similarly, CRH can stimulate the locus coeruleus, a dense collection of autonomic neurons in the brainstem, to secrete norepinephrine [23]. Also, GRs are present in sympathetic neurons which allow glucocorticoids to regulate the synthesis, uptake, and tissue content of norepinephrine [37]. Glucocorticoids can modulate the expression of the $\beta$-adrenergic receptor both through genomic (via the GR) and nongenomic means [38]. Together, catecholamines and glucocorticoids increase cardiovascular output and catabolic effects (e.g., metabolism of glycogen, protein, and triglycerides to provide energy), yet inhibit many body systems, including reproduction and immunity [21,37].

The ability of an animal to perceive a situation as stressful depends on prior experiences and developmental history. Both combine to either sensitize or protect the animal from particular challenges [12]. Behavioral responses to challenges are different depending on the individual, resulting in aggression, submission, humiliation, or adaptation. These responses will either increase or decrease the vulnerability of the animal to subsequent challenges [12]. Furthermore, the stress response of an individual may protect it against certain immune challenges, yet make it susceptible to others [12]. In cattle, the behavioral response to humans, as well as novel environments, has been linked to stress responsiveness. These differences in behavioral responses have been demonstrated to alter immune functions in cattle.

\section{Temperament}

Stress has been linked to certain human behaviors and conditions, including fear, anxiety, and depression [39]. Specifically for fear, Johnson et al. [40] demonstrated in rats that glucocorticoid receptors were present in the lateral amygdala, a region of the brain known for detecting and storing fear memory. Although management procedures may not cause pain, they may act as a psychological stressor by inducing fear, which is a strong stressor in cattle [14]. Cattle are subject to handling and management by humans on a regular basis, which can be stressful. This includes feeding, cleaning, handling and restraint, and immunizations. A negative behavioral response to handling and management procedures can greatly affect productivity. Cattle behavior has come to the forefront in the past several decades. Scott and Fredericson [41] described animals that tried to escape or move away from human contact as "wild," while animals that did not appear agitated by human contact were labeled as "tame." In cattle, changes in behavior, such as their fear response to humans and/or to novel environments is defined as temperament [8]. Stricklin and Kautz-Scanavy [42] described temperament as the degree of skittishness, excitability, apprehension, or calmness of an animal. More temperamental, or wild cattle, increase the risk of injury to facilities, workers, and other cattle, thus increasing costs (i.e., bruising on carcasses) $[7,9]$. Therefore, producers often select for more docile cattle to reduce economic losses.

Many factors can contribute to temperament, including breed, gender, age, previous handling, and genetics [7, 4345]. For example, Bos indicus and Bos indicus-crosses have been reported to be more temperamental then Bos taurus cattle $[46,47]$. Studies also show that steers are calmer than heifers $[7,48]$. Heritability of temperament has been estimated at 0.37 for flight time in weaned Australian cattle (flight time is the denominator for exit velocity, that is, flight time is not a rate as the distance traversed is not divided by time) [49]. Additionally, Hoppe et al. [50] demonstrated that heritability of chute score and flight speed scores (calves scored upon exiting a squeeze chute; $1=$ walk, $2=$ trot, $3=$ run, and 4 = jumping out of chute) were affected by breed, with Herefords having a greater and Limousin having the lowest heritability estimate for both measurements. There are indications that consistent handling early in life and over long periods of time can improve the temperament of cattle and perhaps prevent the negative effects of temperament on carcass quality $[8,14,45,51]$. Furthermore, social interaction 
of cows and calves, specifically isolation versus group raising, can affect behavior, temperament, and growth of calves [42].

In recent years the secretion of stress hormones has been linked to temperament in many species including cattle and mice [11, 52]. For example, mice that overexpress phenylethanolamine-n-methyl transferase (PMNT), the enzyme that converts norepinephrine to epinephrine, produce greater amounts of epinephrine and are more aggressive [52]. A study in humans suggested that cortisol secreted in breast milk may influence infant temperament [53]. In cattle, differences in temperament have been linked to stress responsiveness with more excitable (temperamental) cattle having greater basal concentrations of cortisol than calm cattle $[10,45,54]$. It has also been suggested that temperamental cattle display an endophenotype of chronic stress, due to the chronic nature in which cortisol concentrations are elevated $[11,55]$, as well as depression, as temperamental cattle display a blunted ACTH response to CRH but an enhanced response to VP [55].

3.1. Temperament Measurement. Methods for scoring temperament were developed as early as the 1960s, and over the past 45 years several objective and subjective methods have been utilized [42]. Multiple methods are often employed to improve accuracy, with the three most common measurements being chute score, pen score, and exit velocity (flight speed). Chute score analyzes the temperament of cattle while held in a squeeze chute with head restrained [43]. Cattle are then scored from 1 to 5 based on the amount of movement. Cattle are ranked 1 if there is virtually no movement and ranked 5 if the cattle are continuously struggling.

In contrast, pen score allows measurement of reactivity while the animal is unrestrained. Analysis of temperament by pen score is conducted by separating cattle into small groups ( 3 to 5 animals) and measuring their reactivity to a human observer [56]. In brief, a human observer approaches the group of cattle. The observer then approaches each calf and assigns a score between 1 and 5 based on the calf's reaction to the observer. Calves that are docile, do not react to the observer, and allow the observer to approach are given a score of 1 . A calf given a score of 2 is slightly aggressive, is aware of the observer, and likely stands in a corner away from the observer. Calves that move away from the observer and run with a raised head alongside the fence, fully aware of the position of the observer, are given a score of 3 . A score of 4 is given to calves that are aggressive. They are aware of the observer, may run along the fence or even run into gates or fences. Calves that are scored a 5 (very aggressive) are those that are often called "crazy" and will often run at gates, fences, and humans in an attempt to exit the pen. Calves given a score of 5 are often allowed to exit the pen in order to more accurately determine the scores of the remaining calves (i.e., to avoid the temperamental animals agitating the other calves, especially if they are of a calmer temperament). Both chute and pen score are subjective methods, and therefore increased variation can arise due to differences between observers.

Exit velocity, or flight speed, is emerging as the most objective measurement of temperament in cattle $[10,45$,
57, 58]. Exit velocity $[45,59]$ is an objective measurement defined as the rate $(\mathrm{m} / \mathrm{s})$ at which an animal traverses a specified distance after exiting a squeeze chute. This distance can range from 1 to 2 meters, depending on technique $[7,45,54,60,61]$. Burrow [62] labeled cattle with an exit velocity of $>2.4 \mathrm{~m} / \mathrm{s}$ as temperamental while cattle with an exit velocity of $\leq 1.9 \mathrm{~m} / \mathrm{s}$ were labeled as calm. In order to analyze for differences in calf exit velocity other studies have utilized a ranking system in which cattle are ranked from 1 to 3 based on an animal's deviation from the mean exit velocity for the group of cattle measured $[45,54]$.

As different aspects of behavior may be measured by different assessments [45], it is possible that a combined score utilizing multiple assessments may allow more accurate temperament classification. Recent studies have utilized an average of pen score and exit velocity to assign a temperament score to cattle. Based on temperament score, cattle can be ranked into temperament groups (e.g., calm, intermediate, and temperamental). Studies have demonstrated a correlation between exit velocity and cortisol concentration $(r=0.26, P=.042$ and $r=0.35, P<.01)([54,63]$, resp.). Specifically, cattle with greater measurements of exit velocity have greater basal concentrations of cortisol $[10,45]$. Although both objective and subjective methods are utilized to assess cattle temperament, the exit velocity method has a higher repeatability when compared to pen and chute scores $[45,57]$. Also, Café et al. [61] demonstrated that correlations between temperament measured at 2 different time points was greater for an average of exit velocity and chute score than either measurement alone.

Temperament is most often measured at weaning, and therefore most of the published literature has focused on the effects of temperament during the early preweaning and postweaning periods. Burdick et al. [64] demonstrated that exit velocity can be measured at an earlier age ( 21 to 24 days of age), yet exit velocity measurements made that early in life predicted temperament at weaning $(173 \pm 2$ days of age) in less than $60 \%$ of the calves. An additional study showing the evolution of exit velocity in Brahman calves from 21 days of age through approximately 231 days of age demonstrated that cattle classified as temperamental (based on temperament score) increase their exit velocity at a greater rate than calm and intermediate ranked calves [65].

An effect of sex of cattle on exit velocity is debatable. A previous study, utilizing Braford, Simmental $\times$ Red Angus, Red Brangus, Simbrah, and Tarentaise $\times$ Angus breeds, indicated an effect of sex on temperament score in which female calves (heifers) had a greater temperament score than castrate males (steers) [48]. However, studies by Burdick et al. $[64,65]$ did not find an effect of sex (bull versus heifer) on exit velocity.

3.2. Effect of Temperament on Cattle Production. Temperament can affect virtually all aspects of cattle production, including growth, reproduction, and immunity. For example, studies have determined that cattle with slower exit velocities gain weight more rapidly than those with faster 
exit velocities $[48,51,57,61]$ and more temperamental cattle had lower live weights than did calm cattle [9]. Café et al. [61] also demonstrated that time spent eating was reduced and dry matter intake tended to be reduced in cattle with greater exit velocities. Petherick et al. [66] showed a negative correlation between exit velocity and ADG. Hoppe et al. [50] also demonstrated negative correlations between chute score and flight speed score with ADG. Hafez and Lindsay [67] determined that dairy cattle with both very wild and very calm temperaments have lower conception rates when compared to cows of moderate temperaments. Breuer et al. [68] established that wild temperament in dairy cows was correlated with lower milk yield, milk protein, and milk fat content. Temperament can also affect meat quality in cattle by increasing bruising and carcass $\mathrm{pH}$ and decreasing tenderness $[46,48,51,54,61]$. Cattle with greater exit velocities also had reduced carcass weight and rib fat [61]. Additionally, more nervous cattle have been reported to have a greater carcass bruising or bruise score when compared to calmer cattle $[9,46]$. Furthermore, temperament can diminish immune responsiveness, with more temperamental calves having a reduced response to vaccination when compared with calm calves [69]. Therefore, cattle with excitable temperaments have been suggested to increase production costs due to the increased risk of injury and decreased carcass value [7]. Similar to stress, temperament has also been suggested to negatively affect immune function, as detailed in a later section.

\subsection{Temperament and Immune Function. Recent studies have} indicated negative impacts on immune function in animals that are more temperamental. Cavigelli et al. [70] indicated that mice showing high-locomotion behavior in response to novel stimuli have larger adrenals, greater concentrations of corticosterone, and lower concentrations of the proinflammatory cytokine tumor necrosis factor alpha (TNF- $\alpha$ ) after tail nicking. These mice also had a greater incidence of tumor formation and often died at a younger age than less responsive mice. Therefore, high-responsive mice have a greater HPA axis activation with a coincident hampered immune response. In infant monkeys, Capitanio et al. [71] demonstrated that high-nervous animals had greater cortisol concentrations. Additionally, there were positive correlations between neutrophils and cortisol concentrations in lownervous monkeys, but no relationship between the two variables in high-nervous monkeys.

Along with having negative impacts on growth and carcass quality, poor temperament (i.e., cattle exhibiting greater temperament scores) can negatively affect adaptive immune function of cattle. In a study conducted in Brahman steers, temperamental steers had lower in vitro lymphocyte proliferation and lower in vivo vaccine-specific IgG concentrations when compared to calm steers [69]. In another study temperament scores were negatively correlated with serum concentrations of IgG, as well as with the ability of isolated lymphocytes to produce IgM and proliferate [72]. However, there is limited documentation of the influence of temperament on immune function in cattle. Specifically, the influence of temperament on the production of stress hormones in response to an immune challenge has yet to be studied in sufficient detail.

Studies using chronic stressors in mice have found changes in immune function. For example, mice exposed to social defeat stress multiple times have been found to have developed glucocorticoid resistance (as discussed previously), increasing the probability of mice dying from endotoxic shock or developing neurodegenerative conditions [73-75]. Additionally, elevated glucocorticoids have been demonstrated to impair clearance of bacteria from wounds and wound healing. However, glucocorticoid resistance may be beneficial in mice that are more aggressive, as this allows wounds to heal more quickly in the presence of greater concentrations of glucocorticoids. In cattle it remains unclear whether the greater basal concentrations of glucocorticoids and catecholamines, characteristic of temperamental cattle, are immunosuppressive, or whether, in response to specific challenges, stress hormones can be beneficial.

\section{Conclusion}

Numerous physiological and psychological conditions determine the health and subsequent growth of calves. In the past decade there has been a great increase in the study of temperament and its effect on calf health and growth. Cattle with faster exit velocities and greater temperament scores have been shown to be less productive. Temperament score, exit velocity, and pen score have been correlated with measurements of stress, including cortisol and epinephrine. Additionally, temperament has been linked to decreased lymphocyte proliferation and an inhibited humoral immune response. Collectively, the findings reported in this paper suggest that there is a link between stress responsiveness, temperament, and immunity in cattle. Due to interactions of the stress response and temperament, immune function may be altered in more temperamental animals.

\section{Disclosure}

Mention of trade names or commercial products in this paper is solely for the purpose of providing specific information and does not imply recommendation or endorsement by the U.S. Department of Agriculture.

\section{References}

[1] H. R. Crookshank, M. H. Elissalde, R. G. White, D. C. Clanton, and H. E. Smalley, "Effect of transportation and handling of calves upon blood serum composition," Journal of Animal Science, vol. 48, no. 3, pp. 430-435, 1979.

[2] F. C. Rulofson, D. E. Brown, and R. A. Bjur, "Effect of blood sampling and shipment to slaughter on plasma catecholamine concentrations in bulls," Journal of Animal Science, vol. 66, no. 5, pp. 1223-1229, 1988.

[3] D. C. Lay Jr., T. H. Friend, R. D. Randel, C. L. Bowers, K. K. Grissom, and O. C. Jenkins, "Behavioral and physiological effects of freeze or hot-iron branding on crossbred cattle," Journal of Animal Science, vol. 70, no. 2, pp. 330-336, 1992. 
[4] G. A. Carrasco and L. D. Van De Kar, "Neuroendocrine pharmacology of stress," European Journal of Pharmacology, vol. 463, no. 1-3, pp. 235-272, 2003.

[5] E. Charmandari, C. Tsigos, and G. Chrousos, "Endocrinology of the stress response," Annual Review of Physiology, vol. 67, pp. 259-284, 2005.

[6] K. R. Buckham Sporer, P. S. D. Weber, J. L. Burton, B. Earley, and M. A. Crowe, "Transportation of young beef bulls alters circulating physiological parameters that may be effective biomarkers of stress," Journal of Animal Science, vol. 86, no. 6, pp. 1325-1334, 2008.

[7] H. M. Burrow, "Measurements of temperament and their relationship with performance traits in beef cattle," Animal Breeding Abstracts, vol. 65, pp. 477-495, 1997.

[8] G. Fordyce, R. M. Dodt, and J. R. Wythes, "Cattle temperaments in extensive beef herds in northern Queensland. 1. Factors affecting temperament," Australian Journal of Experimental Agriculture, vol. 28, pp. 683-687, 1988.

[9] G. Fordyce, M. E. Goddard, R. Tyler, G. Williams, and M. A. Toleman, "Temperament and bruising of Bos indicus cross cattle," Australian Journal of Experimental Agriculture, vol. 25, pp. 283-288, 1985.

[10] L. R. Fell, I. G. Colditz, K. H. Walker, and D. L. Watson, “Associations between temperament, performance and immune function in cattle entering a commercial feedlot," Australian Journal of Experimental Agriculture, vol. 39, no. 7, pp. 795-802, 1999.

[11] K. O. Curley Jr., D. A. Neuendorff, A. W. Lewis, J. J. Cleere, T. H. Welsh, and R. D. Randel, "Functional characteristics of the bovine hypothalamic-pituitary-adrenal axis vary with temperament," Hormones and Behavior, vol. 53, no. 1, pp. 20 27, 2008.

[12] B. S. McEwen, C. A. Biron, K. W. Brunson et al., "The role of adrenocorticoids as modulators of immune function in health and disease: neural, endocrine and immune interactions," Brain Research Reviews, vol. 23, no. 1-2, pp. 79-133, 1997.

[13] P. Le Neindre, X. Boivin, and A. Boissy, "Handling of extensively kept animals," Applied Animal Behaviour Science, vol. 49, no. 1, pp. 73-81, 1996.

[14] T. Grandin, "Assessment of stress during handling and transport," Journal of Animal Science, vol. 75, no. 1, pp. 249257, 1997.

[15] K. E. Boandl, J. E. Wohlt, and R. V. Carsia, "Effects of handling, administration of a local anesthetic, and electrical dehorning on plasma cortisol in Holstein calves," Journal of Dairy Science, vol. 72, no. 8, pp. 2193-2197, 1989.

[16] H. Selye, "A syndrome produced by diverse nocuous agents," Nature, vol. 138, no. 3479, p. 32, 1936.

[17] W. B. Cannon, "Organization for physiological homeostasis," Physiology Reviews, vol. 9, pp. 399-431, 1929.

[18] W. B. Cannon, The Wisdom of the Body, W. W. Norton, New York, NY, USA, 1932.

[19] K. Pacák and M. Palkovits, "Stressor specificity of central neuroendocrine responses: implications for stress-related disorders," Endocrine Reviews, vol. 22, no. 4, pp. 502-548, 2001.

[20] G. P. Chrousos and T. Kino, "Interactive functional specificity of the stress and immune responses: the Ying, the Yang, and the defense against 2 major classes of bacteria," Journal of Infectious Diseases, vol. 192, no. 4, pp. 551-555, 2005.

[21] S. K. Butcher and J. M. Lord, "Stress responses and innate immunity: aging as a contributory factor," Aging Cell, vol. 3, no. 4, pp. 151-160, 2004.
[22] G. Aguilera, "Corticotropin releasing hormone, receptor regulation and the stress response," Trends in Endocrinology and Metabolism, vol. 9, no. 8, pp. 329-336, 1998.

[23] P. H. Black, "Stress and the inflammatory response: a review of neurogenic inflammation," Brain, Behavior, and Immunity, vol. 16, no. 6, pp. 622-653, 2002.

[24] P. M. Plotsky, "Pathways to the secretion of adrenocorticotropin: a view from the portal," Journal of Neuroendocrinology, vol. 3, no. 1, pp. 1-9, 1991.

[25] D. M. Gibbs and W. Vale, "Presence of corticotropin releasing factor-like immunoreactivity in hypophysial portal blood," Endocrinology, vol. 111, no. 4, pp. 1418-1420, 1982.

[26] J. I. Webster Marketon and R. Glaser, "Stress hormones and immune function," Cellular Immunology, vol. 252, no. 1-2, pp. 16-26, 2008.

[27] G. B. Makara, E. Stark, M. Kárteszi, M. Palkovits, and G. Rappay, "Effects of paraventricular lesions on stimulated ACTH release and CRF in stalk-median eminence of the rat," The American journal of physiology, vol. 240, no. 4, pp. E441E446, 1981.

[28] J. J. Watters, M. W. Swank, C. W. Wilkinson, and D. M. Dorsa, "Evidence for glucocorticoid regulation of the rat vasopressin V receptor gene," Peptides, vol. 17, no. 1, pp. 67-73, 1996.

[29] L. V. Scott and T. G. Dinan, "Vasopressin and the regulation of hypothalamic-pituitary-adrenal axis function: implications for the pathophysiology of depression," Life Sciences, vol. 62, no. 22, pp. 1985-1998, 1998.

[30] C. Tsigos and G. P. Chrousos, "Hypothalamic-pituitaryadrenal axis, neuroendocrine factors and stress," Journal of Psychosomatic Research, vol. 53, no. 4, pp. 865-871, 2002.

[31] J. D. Ashwell, F. W. M. Lu, and M. S. Vacchio, "Glucocorticoids in T cell development and function," Annual Review of Immunology, vol. 18, pp. 309-345, 2000.

[32] T. Rhen and J. A. Cidlowski, "Antiinflammatory action of glucocorticoids-new mechanisms for old drugs," New England Journal of Medicine, vol. 353, no. 16, pp. 1711-1658, 2005.

[33] K. A. Smoak and J. A. Cidlowski, "Glucocorticoid signaling in health and disease," NeuroImmune Biology, vol. 7, pp. 33-53, 2008.

[34] M. Löwenberg, C. Stahn, D. W. Hommes, and F. Buttgereit, "Novel insights into mechanisms of glucocorticoid action and the development of new glucocorticoid receptor ligands," Steroids, vol. 73, no. 9-10, pp. 1025-1029, 2008.

[35] R. M. Sapolsky, L. M. Romero, and A. U. Munck, "How do glucocorticoids influence stress responses? Integrating permissive, suppressive, stimulatory, and preparative actions," Endocrine Reviews, vol. 21, no. 1, pp. 55-89, 2000.

[36] H. O. Besedovsky and A. Del Rey, "Immune-neuro-endocrine interactions: facts and hypotheses," Endocrine Reviews, vol. 17, no. 1, pp. 64-102, 1996.

[37] G. P. Chrousos and P. W. Gold, "The concepts of stress and stress system disorders: overview of physical and behavioral homeostasis," Journal of the American Medical Association, vol. 267, no. 9, pp. 1244-1252, 1992.

[38] K. Janssens, O. Krylyshkina, N. Hersmus, H. Vankelecom, and C. Denef, " $\beta 1$-adrenoceptor expression in rat anterior pituitary gonadotrophs and in mouse $\alpha \mathrm{T} 3-1$ and $\mathrm{L} \beta \mathrm{T} 2$ gonadotrophic cell lines," Endocrinology, vol. 149, no. 5, pp. 2313-2324, 2008.

[39] A. R. Tyrka, L. M. Wier, L. H. Price et al., "Cortisol and ACTH responses to the Dex/CRH Test: Influence of temperament," Hormones and Behavior, vol. 53, no. 4, pp. 518-525, 2008. 
[40] L. R. Johnson, C. Farb, J. H. Morrison, B. S. McEwen, and J. E. LeDoux, "Localization of glucocorticoid receptors at postsynaptic membranes in the lateral amygdala," Neuroscience, vol. 136, no. 1, pp. 289-299, 2005.

[41] J. P. Scott and E. Fredericson, "The causes of fighting in mice and rats," Physiological Zoology, vol. 4, pp. 273-309, 1951.

[42] W. R. Stricklin and C. C. Kautz-Scanavy, "The role of behavior in cattle production: a review of research," Applied Animal Ethology, vol. 11, no. 4, pp. 359-390, 1984.

[43] T. Grandin, "Behavioral agitation during handling of cattle is persistent over time," Applied Animal Behaviour Science, vol. 36, no. 1, pp. 1-9, 1993.

[44] R. C. Vann, J. W. Holloway, G. E. Carstens, M. E. Boyd, and R. D. Randel, "Influence of calf genotype on colostral immunoglobulins in Bos taurus and Bos indicus cows and serum immunoglobulins in their calves," Journal of Animal Science, vol. 73, no. 10, pp. 3044-3050, 1995.

[45] K. O. Curley Jr., J. C. Paschal, T. H. Welsh, and R. D. Randel, "Technical note: exit velocity as a measure of cattle temperament is repeatable and associated with serum concentration of cortisol in Brahman bulls," Journal of Animal Science, vol. 84, no. 11 , pp. 3100-3103, 2006.

[46] G. Fordyce, J. R. Wythes, W. R. Shorthose, D. W. Underwood, and R. K. Shepherd, "Cattle temperaments in extensive beef herds in northern Queensland. 2. Effect of temperament on carcass and meat quality," Australian Journal of Experimental Agriculture, vol. 28, pp. 689-693, 1988.

[47] H. M. Burrow, "Variances and covariances between productive and adaptive traits and temperament in a composite breed of tropical beef cattle," Livestock Production Science, vol. 70, no. 3, pp. 213-233, 2001.

[48] B. D. Voisinet, T. Grandin, J. D. Tatum, S. F. O'Connor, and J. J. Struthers, "Feedlot cattle with calm temperaments have higher average daily gains than cattle with excitable temperaments," Journal of Animal Science, vol. 75, no. 4, pp. 892-896, 1997.

[49] K. C. Prayaga and J. M. Henshall, "Adaptability in tropical beef cattle: genetic parameters of growth, adaptive and temperament traits in a crossbred population," Australian Journal of Experimental Agriculture, vol. 45, no. 7-8, pp. 971983, 2005.

[50] S. Hoppe, H. R. Brandt, S. König, G. Erhardt, and M. Gauly, "Temperament traits of beef calves measured under field conditions and their relationships to performance," Journal of Animal Science, vol. 88, no. 6, pp. 1982-1989, 2010.

[51] H. M. Burrow and R. D. Dillon, "Relationships between temperament and growth in a feedlot and commercial carcass traits of Bos indicus crossbreds," Australian Journal of Experimental Agriculture, vol. 37, no. 4, pp. 407-411, 1997.

[52] D. B. Sørensen, P. F. Johnsen, B. M. Bibby et al., "PNMT transgenic mice have an aggressive phenotype," Hormone and Metabolic Research, vol. 37, no. 3, pp. 159-163, 2005.

[53] L. M. Glynn, E. P. Davis, C. D. Schetter, A. Chicz-DeMet, C. J. Hobel, and C. A. Sandman, "Postnatal maternal cortisol levels predict temperament in healthy breastfed infants," Early Human Development, vol. 83, no. 10, pp. 675-681, 2007.

[54] D. A. King, C. E. Schuehle Pfeiffer, R. D. Randel et al., "Influence of animal temperament and stress responsiveness on the carcass quality and beef tenderness of feedlot cattle," Meat Science, vol. 74, no. 3, pp. 546-556, 2006.

[55] K. O. Curley, D. A. Neuendorff, A. W. Lewis, F. M. Rouquette, R. D. Randel, and T. H. Welsh, "The effectiveness of vasopressin as an ACTH secretagogue in cattle differs with temperament," Physiology and Behavior, vol. 101, no. 5, pp. 699-704, 2010.
[56] A. C. Hammond, T. A. Olson, C. C. Chase et al., "Heat tolerance in two tropically adapted Bos taurus breeds, senepol and romosinuano, compared with Brahman, Angus, and Hereford Cattle in Florida," Journal of Animal Science, vol. 74, no. 2, pp. 295-303, 1996.

[57] R. Müller and M. A. G. von Keyserlingk, "Consistency of flight speed and its correlation to productivity and to personality in Bos taurus beef cattle," Applied Animal Behaviour Science, vol. 99, no. 3-4, pp. 193-204, 2006.

[58] R. C. Vann, J. A. Parish, and W. B. McKinley, "Case Study: Mississippi cattle producers gain insight into temperament effects of feedlot performance and subsequent meat quality," Professional Animal Scientist, vol. 24, pp. 628-633, 2008.

[59] H. M. Burrow, G. W. Seifert, and N. J. Corbet, "A new technique for measuring temperament in cattle," Proceedings of the Australian Society for Animal Production, vol. 17, pp. 154-157, 1988.

[60] L. M. Cafe, B. L. McIntyre, D. L. Robinson, G. H. Geesink, W. Barendse, and P. L. Greenwood, "Production and processing studies on calpain-system gene markers for tenderness in brahman cattle: 1. growth, efficiency, temperament, and carcass characteristics," Journal of Animal Science, vol. 88, no. 9, pp. 3047-3058, 2010.

[61] L. M. Café, D. L. Robinson, D. M. Ferguson, B. L. McIntyre, G. H. Geesink, and P. L. Greenwood, "Cattle temperament: persistence of assessments and associations with productivity, efficiency, carcass and meat quality traits," Journal of Animal Science, vol. 89, no. 5, pp. 1452-1465, 2011.

[62] H. M. Burrow, "Effect of intensive handling of zebu crossbred weaner calves on temperament," Proceedings of the Australian Association for Animal Breeding and Genetics, vol. 9, pp. 208211, 1991.

[63] K. O. Curley Jr., Influence of temperament on bovine hypothalamic-pituitary-adrenal function, M.S. thesis, Texas A\&M University, College Station, 2004.

[64] N. C. Burdick, J. P. Banta, D. A. Neuendorff et al., "Interrelationships among growth, endocrine, immune, and temperament variables in neonatal Brahman Calves," Journal of Animal Science, vol. 87, no. 10, pp. 3202-3210, 2009.

[65] N. C. Burdick, B. Agado, J. C. White et al., "Evolution of exit velocity in suckling Brahman calves," Journal of Animal Science, vol. 89, no. 1, pp. 233-236, 2011.

[66] J. C. Petherick, R. G. Holroyd, and A. J. Swain, "Performance of lot-fed Bos indicus steers exposed to aspects of a feedlot environment before lot-feeding," Australian Journal of Experimental Agriculture, vol. 43, no. 10, pp. 1181-1191, 2003.

[67] E. S. E. Hafez and D. R. Lindsay, "Behavioral responses in farm animals and their relevance to research techniques," Animal Breeding Abstracts, vol. 33, pp. 1-16, 1965.

[68] K. Breuer, P. H. Hemsworth, J. L. Barnett, L. R. Matthews, and G. J. Coleman, "Behavioral response to humans and the productivity of commercial dairy cows," Applied Animal Behavior Science, vol. 66, pp. 273-288, 2000.

[69] R. A. Oliphint, Evaluation of the inter-relationships of temperament, stress responsiveness and immune function in beef calves, M.S. thesis, Texas A\&M University, College Station, 2006.

[70] S. A. Cavigelli, J. M. Bennett, K. C. Michael, and L. C. Klein, "Female temperament, tumor development and life span: relation to glucocorticoid and tumor necrosis factor $\alpha$ levels in rats," Brain, Behavior, and Immunity, vol. 22, no. 5, pp. 727735, 2008.

[71] J. P. Capitanio, S. P. Mendoza, and S. W. Cole, "Nervous temperament in infant monkeys is associated with reduced 
sensitivity of leukocytes to cortisol's influence on trafficking," Brain, Behavior, and Immunity, vol. 25, no. 1, pp. 151-159, 2011.

[72] M. E. Bauer, P. Perks, S. L. Lightman, and N. Shanks, "Restraint stress is associated with changes in glucocorticoid immunoregulation," Physiology and Behavior, vol. 73, no. 4, pp. 525-532, 2001.

[73] R. Avitsur, D. A. Padgett, and J. F. Sheridan, "Social Interactions, Stress, and Immunity," Neurologic Clinics, vol. 24, no. 3, pp. 483-491, 2006.

[74] R. R. Johnson, R. Storts, T. H. Welsh Jr., C. J. R. Welsh, and M. W. Meagher, "Social stress alters the severity of acute Theiler's virus infection," Journal of Neuroimmunology, vol. 148, no. 12, pp. 74-85, 2004.

[75] E. E. Young, T. W. Prentice, D. Satterlee et al., "Glucocorticoid exposure alters the pathogenesis of Theiler's murine encephalomyelitis virus during acute infection," Physiology and Behavior, vol. 95, no. 1-2, pp. 63-71, 2008. 

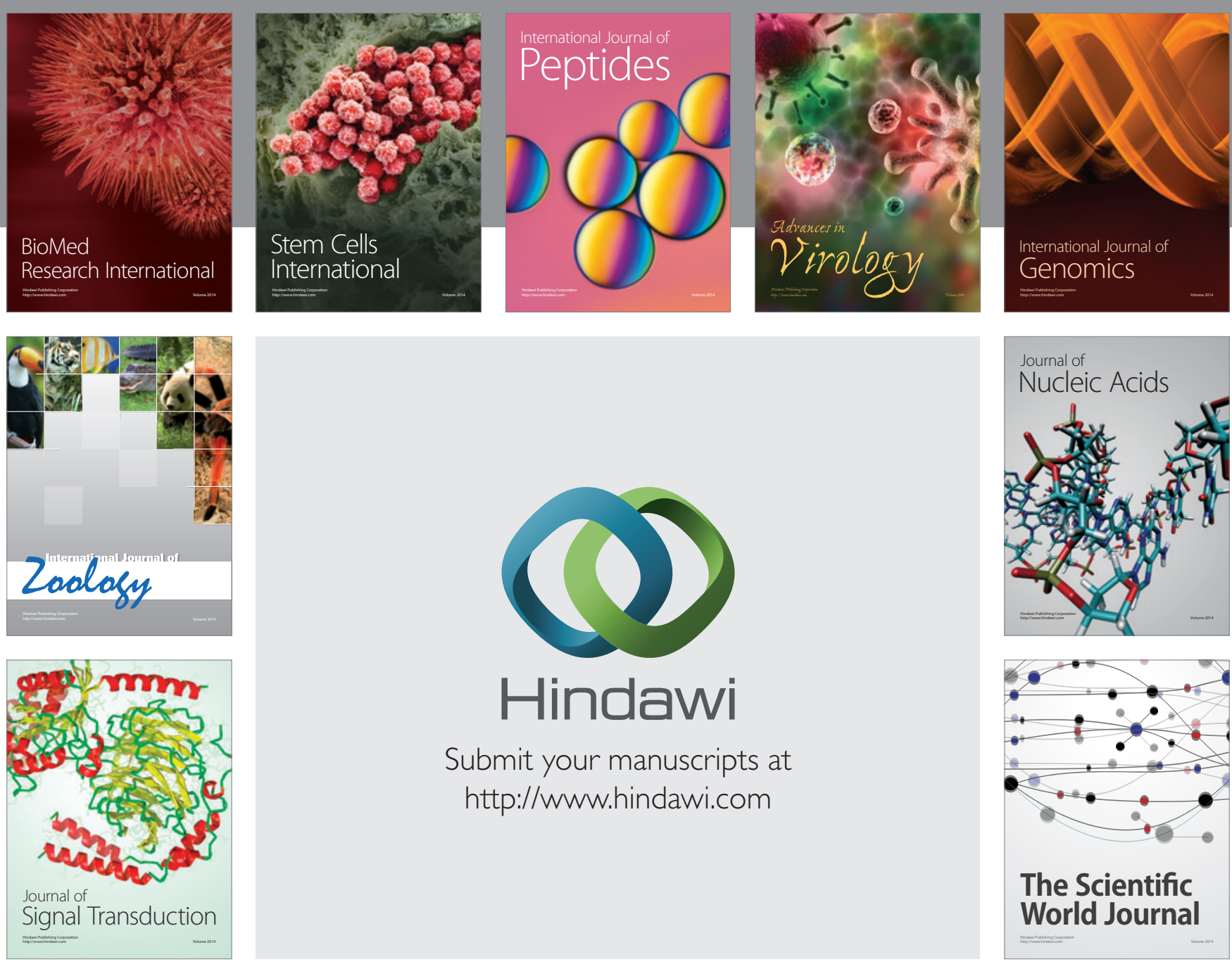

Submit your manuscripts at

http://www.hindawi.com
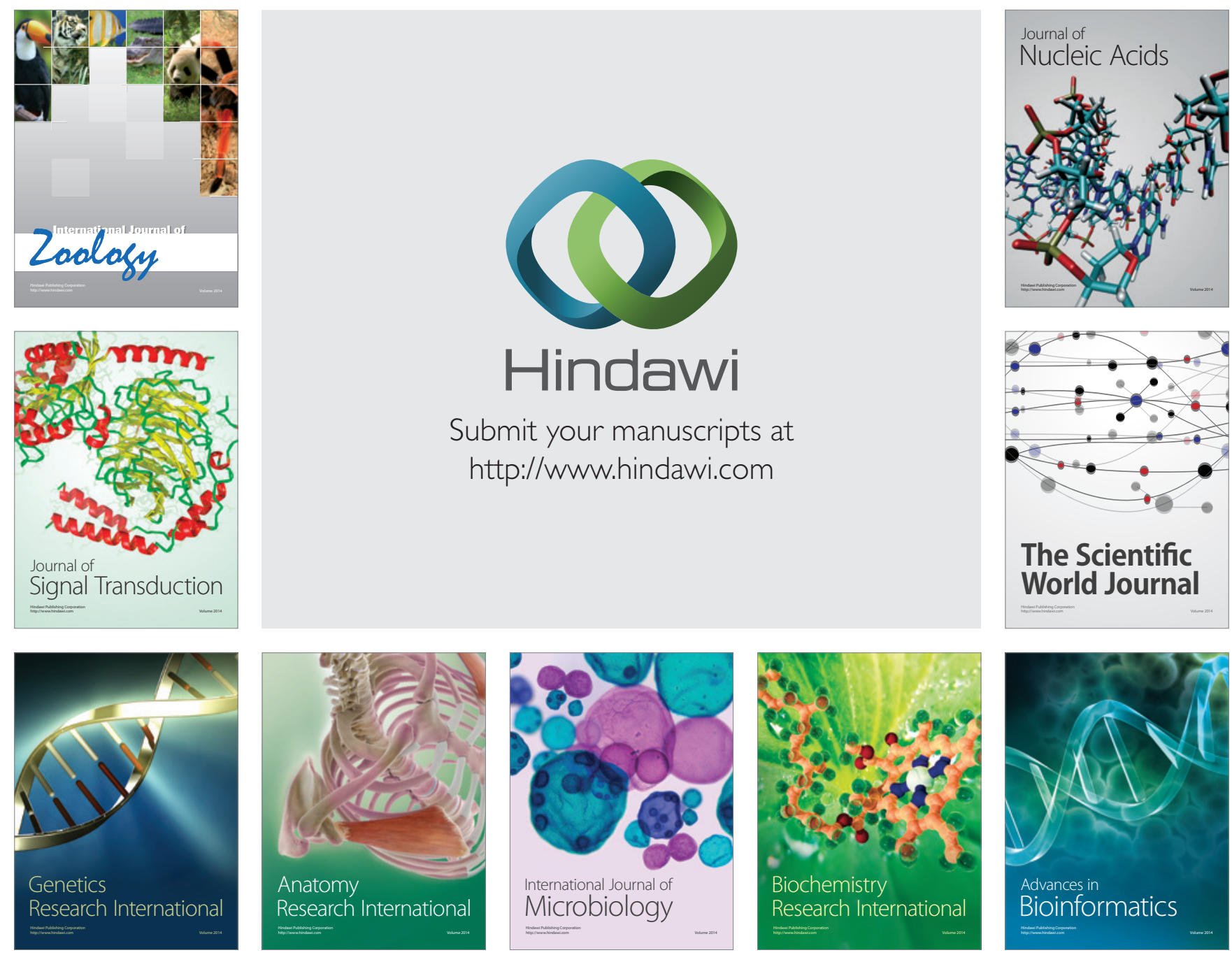

The Scientific World Journal
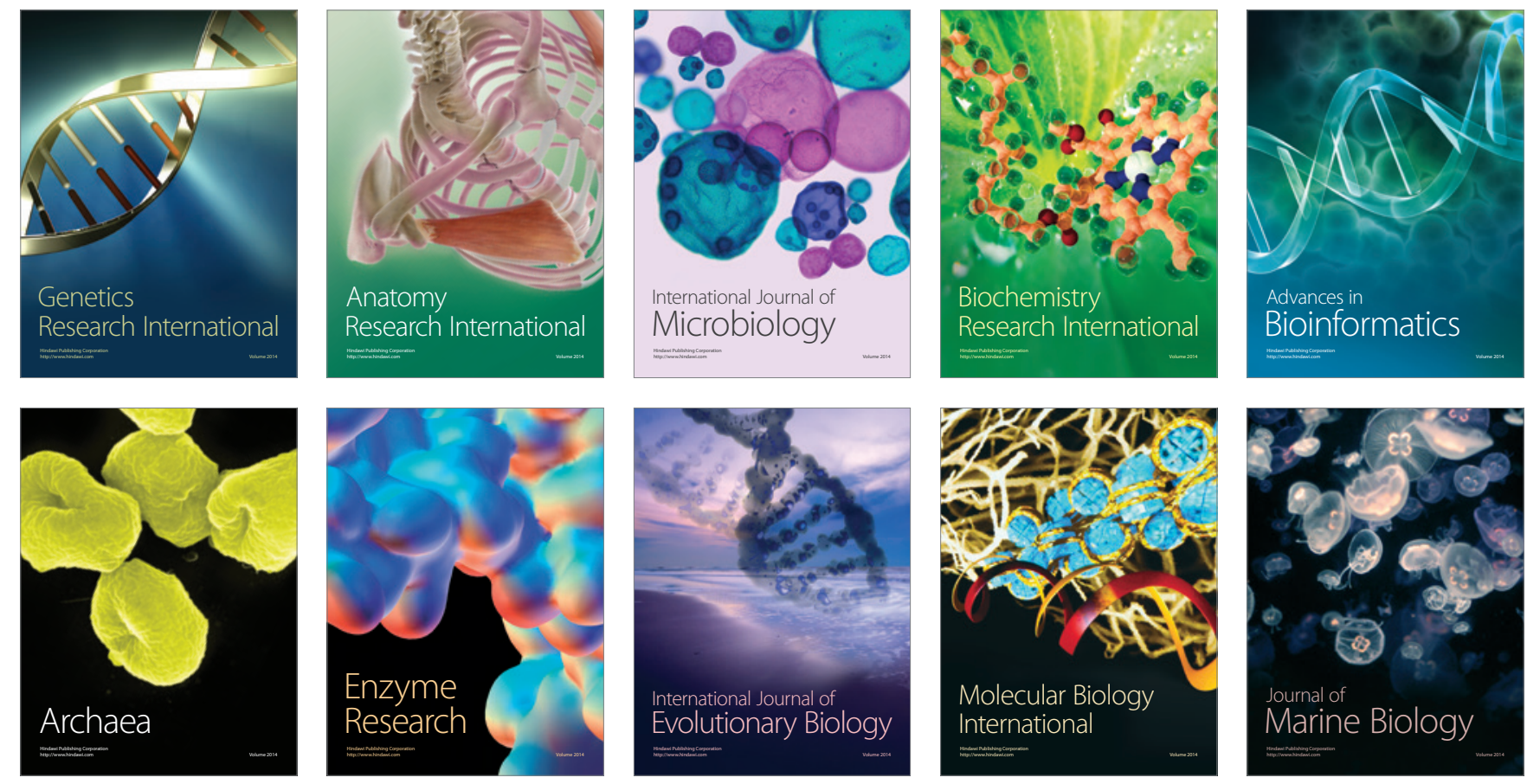